\title{
Effectiveness of open-label losartan/ hydrochlorothiazide combination therapy in Asian patients with hypertension not controlled with ACE inhibitor or ARB monotherapy
}

\author{
Kee-Sik Kim ${ }^{1}$, Wei Hu Fan ${ }^{2}$, Young-Dae Kim ${ }^{3}$, Wenling Zhu ${ }^{4}$, Yen Yew Ngau ${ }^{5}$, Peter Tong ${ }^{6}$, Byung-Soo Kim ${ }^{7}$, \\ Maureen Santos $^{8}$, Wei-Hsiang Lin ${ }^{9}$, Peera Buranakitjaroen ${ }^{10}$, Rachid Massaad ${ }^{11}$ and Ronald D Smith ${ }^{12}$, for the \\ Asia HEAALTH Study Investigators
}

Antihypertensive efficacy and safety of losartan/hydrochlorothiazide (HCTZ) combinations have not been adequately studied in Asians. In this open-label, 12-week study in seven Asian areas, patients on monotherapy with angiotensin receptor blockers (ARBs) or angiotensin-converting enzyme inhibitors (ACEls) but not at blood pressure (BP) goal (sitting diastolic BP (SiDBP) $<90 \mathrm{~mm} \mathrm{Hg}$ in non-diabetics and $<80 \mathrm{~mm} \mathrm{Hg}$ in diabetics) were switched to losartan $50 \mathrm{mg} / \mathrm{HCTZ} 12.5 \mathrm{mg}$. At 4 and 8 weeks, the therapy for patients not at goal BP was titrated to losartan $100 \mathrm{mg} / \mathrm{HCTZ} 12.5 \mathrm{mg}$ and to losartan $100 \mathrm{mg} / \mathrm{HCTZ} 25 \mathrm{mg}$, respectively. Data analysis included 430 patients with mean (s.d.) age $53.0(10.1)$ years and $51.9 \%$ of the female gender. After 8 weeks (primary end point; titration up to losartan $100 \mathrm{mg} / \mathrm{HCTZ} 12.5 \mathrm{mg}$ ), 73.5\% (95\% confidence interval (Cl): 69.0-77.6) of patients reached BP goal; 63.4 and $78.1 \%$ of patients reached BP goal at 4 weeks (titration up to losartan $50 \mathrm{mg} / \mathrm{HCTZ}$ $12.5 \mathrm{mg}$ ) and at 12 weeks (titration up to losartan $100 \mathrm{mg} / \mathrm{HCTZ} 25 \mathrm{mg}$ ). The mean changes from baseline $(95 \% \mathrm{Cl})$ in sitting systolic BP and SiDBP at 8 weeks were $-16.7(-18.0$ to -15.4$) \mathrm{mm} \mathrm{Hg}$ and $-12.1(-12.9$ to -11.4$) \mathrm{mm} \mathrm{Hg}$, respectively. Clinical and laboratory adverse experiences (AEs) were reported in 27.5 and $21.0 \%$ of patients, respectively. Nine patients were discontinued because of drug-related clinical AEs. Switching Asian patients currently not at BP goal with ARB or ACEI monotherapy to a losartan/HCTZ combination achieved BP goal in the majority of patients. Losartan/HCTZ combinations were generally well tolerated.

Hypertension Research (2009) 32, 520-526; doi:10.1038/hr.2009.42; published online 24 April 2009

Keywords: angiotensin-converting enzyme inhibitors; angiotensin receptor blockers; Asian patients; combination therapy; hypertension treatment; losartan/hydrochlorothiazide combination

\section{INTRODUCTION}

The recent report of the Asia-Pacific Cohort Studies Collaboration that analyzed available data from 15 countries in the Asia-Pacific region suggested that 'up to $66 \%$ of some subtypes of cardiovascular disease can be attributed to hypertension underscoring the immense impact that blood pressure (BP)-lowering strategies could have in this populous region.' ${ }^{1}$ The prevailing global definition of essential hypertension is clinic arterial diastolic BP (DBP) $>90 \mathrm{~mm} \mathrm{Hg}$ or systolic BP (SBP) $>140 \mathrm{~mm} \mathrm{Hg}^{2-4}$ Using this definition, the non-age-adjusted prevalence of hypertension is high in most countries in the AsiaPacific region, including those involved in this study. ${ }^{1}$

The reduction in BP is the primary goal of current international hypertension treatment guidelines, such as those from the International Society of Hypertension/World Health Organization (ISH/ WHO), the European Society of Hypertension/European Society of Cardiology (ESH/ESC) and The Seventh Report of the Joint National Committee on Prevention, Detection, Evaluation, and Treatment of High Blood Pressure (JNC-7). ${ }^{2-4}$ Combination therapy has been

${ }^{1}$ Department of Internal Medicine, Daegu Catholic University Medical Center, Daegu, Republic of Korea; ${ }^{2}$ Department of Internal Medicine, Huashan Hospital, Shanghai, China; ${ }^{3}$ Department of Internal Medicine, Dong-A University Hospital, Busan, Republic of Korea; ${ }^{4}$ Department of Internal Medicine, Peking Union Medical College Hospital, Beijing, China; ${ }^{5}$ Department of Internal Medicine, Hospital Kuala Lumpur, Kuala Lumpur, Malaysia; ${ }^{6}$ Department of Internal Medicine, Prince of Wales Hospital, The Chinese University of Hong Kong, Hong Kong; ${ }^{7}$ Department of Internal Medicine, Dae-Dong Hospital, Busan, Republic of Korea; ${ }^{8}$ Department of Internal Medicine, Cebu Doctors' University Hospital, Cebu, Philippines; ${ }^{9}$ Department of Internal Medicine, Tri-Service General Hospital, Taipei City, Taiwan; ${ }^{10}$ Department of Internal Medicine, Siriraj Hospital, Mahidol University, Bangkok, Thailand; ${ }^{11}$ MSD (Europe) Inc., Brussels, Belgium and ${ }^{12}$ Merck and Co. Inc., Whitehouse Station, NJ, USA

Correspondence: Dr K-S Kim, Department of Internal Medicine, Daegu Catholic University Medical Center, 3056-6, Daemyung 4 Dong, Namgu Deagu 705-718, Republic of Korea.

E-mail: kks7379@cu.ac.kr

This trial is registered on www.clinicaltrials.gov as NCT00354991.

Received 7 November 2008; revised 7 March 2009; accepted 15 March 2009; published online 24 April 2009 
recognized to achieve lower BP goals, and these guidelines discuss the choice and use of combination therapy. The combination of diuretics with angiotensin-converting enzyme inhibitors (ACEIs) or angiotensin receptor blockers (ARBs) is based on their complementary mechanisms of action (for example, to increase sodium excretion with blockade of angiotensin II-induced vasoconstriction). ${ }^{5}$ It is well established that the combination of an ARB and hydrochlorothiazide (HCTZ) produces more substantial BP responses than monotherapy with either component. ${ }^{6}$

Losartan was the first compound in the ARB therapeutic class. The efficacy and safety of losartan alone and in combination with HCTZ has been well documented, albeit in mostly non-Asian patients. ${ }^{7,8}$ Long-term beneficial effects of the losartan/HCTZ combination have been shown to be lowering $\mathrm{BP}$ and also reducing the risk of hypertensive changes such as left ventricular hypertrophy ${ }^{9}$ and proteinuria $^{10}$ and end points such as end-stage renal disease ${ }^{11}$ and stroke. $^{12}$

The majority of clinical evidence with losartan/HCTZ has been in non-Asian patients. There have been few studies with losartan $100 \mathrm{mg} / \mathrm{HCTZ} 12.5 \mathrm{mg}$. This combination has been developed because studies suggest that the optimal dose of losartan to reduce proteinuria is $100 \mathrm{mg} \mathrm{day}^{-1} .^{13-15}$ In addition, although unwanted effects of diuretics are usually seen at higher doses (for example, HCTZ $>50 \mathrm{mg}),{ }^{16}$ some physicians prefer to use HCTZ $12.5 \mathrm{mg}$. The present study, the Asian Hypertension Evaluation of Angiotensin II Antagonist Losartan+HCTZ (HEAALTH) study, was therefore undertaken to evaluate the antihypertensive effects and safety of the losartan/ HCTZ combinations, especially losartan $100 \mathrm{mg} / \mathrm{HCTZ} 12.5 \mathrm{mg}$, in Asian patients who were not currently at BP goal with prior monotherapy of the usual (submaximal) doses of ACEIs or ARBs.

\section{METHODS}

\section{Study sites and ethics}

This study was conducted at 32 centers within seven Asian countries and areas (China, Hong Kong, Korea, Malaysia, the Philippines, Taiwan and Thailand). The study protocol was approved by the institutional review board at each clinical center. All patients gave written informed consent to participate in the study, in accordance with the Declaration of Helsinki. Execution and monitoring of the study were conducted in accordance with requirements of good clinical practice.

\section{Patient selection}

Eligible patients had essential hypertension (sitting DBP (SiDBP) $\geqslant 90$ to $<110 \mathrm{~mm} \mathrm{Hg}$ in non-diabetic and SiDBP $\geqslant 80$ to $<100 \mathrm{~mm} \mathrm{Hg}$ in diabetic patients), were men or women $\geqslant 18$ years old and were Asian. Patients were excluded from the study if there was any evidence of clinically significant hematological, renal, hepatic or gastrointestinal tract problems; known drug hypersensitivities; or diseases involving the cerebrovascular, immune or cardiovascular systems, including myocardial infarction or left ventricular dysfunction (ejection fraction $\leqslant 50 \%$ ). Patients were also excluded from the study because of the concomitant use of antihypertensive medications, lithium, psychotropic agents or antidepressants; non-steroidal anti-inflammatory drugs, cyclooxygenase II inhibitors or daily high-dose aspirin; astemizole, terfenadine or any other agent with an effect on BP. Pregnant or breastfeeding women were ineligible.

\section{Study procedures}

This was an open-label, multicenter study consisting of a 1-week screening/ baseline period on antihypertensive monotherapy (visits 1 and 2) and a 12week losartan/HCTZ treatment period. Therapy was initiated as losartan $50 \mathrm{mg} / \mathrm{HCTZ} 12.5 \mathrm{mg}$ and, if the BP goal was not reached, titrated to losartan $100 \mathrm{mg} / \mathrm{HCTZ} 12.5 \mathrm{mg}$ at 4 weeks and to losartan $100 \mathrm{mg} / \mathrm{HCTZ} 25 \mathrm{mg}$ at 8 weeks. Of the 512 patients screened, 437 who met the eligibility and whose BP was not controlled on antihypertensive monotherapy (SiDBP $\geqslant 90 \mathrm{~mm} \mathrm{Hg}$ in non-diabetic and SiDBP $\geqslant 80 \mathrm{~mm} \mathrm{Hg}$ in diabetic patients) were enrolled into the treatment period at visit 2 and switched to the losartan $50 \mathrm{mg} / \mathrm{HCTZ}$ $12.5 \mathrm{mg}$ fixed-dose combination. All laboratory testing for each visit was conducted at local laboratories and, except for the screening visit, all clinic visits had to be carried out before 1200 noon to ensure that the BP measurements were performed at trough $22-26 \mathrm{~h}$ after the last dose of study medication.

\section{Study medications}

All study medications were obtained from local sources and administered open label. Patients were instructed to take all study medications regularly between 0600 and 1000 hours after breakfast in the morning of every study day, except on days when a clinic visit was scheduled. On the day of the clinic visit, the study medication was given at the conclusion of the visit. Pill count was checked at each visit to evaluate patient compliance.

\section{Methods of observation}

Trough sitting BP (using a mercury sphygmomanometer) and heart rate and standing (St) BP were measured at the beginning of every clinic visit. Patients sat for at least $5 \mathrm{~min}$ before sitting BPs were recorded. Sitting BP was determined from an average of three measurements obtained 1-2 min apart. None of the three consecutive SiDBP readings could be $>5 \mathrm{~mm} \mathrm{Hg}$ from the calculated average of the three readings. Patients stood for at least $1 \mathrm{~min}$ prior to St BP measurements. Only one reading was measured for St BP measurements. A 12-lead ECG was obtained at the beginning of the study.

All observed or volunteered adverse experiences (AEs) were recorded at each visit. Standard laboratory tests were performed at all visits.

\section{Analysis plan and statistical methods}

The primary variable was the percentage of patients who reached the BP goal after 8 weeks of treatment with the losartan/HCTZ combination (that is, week 8 was considered as the primary time point of the study). Patients were considered as having reached the BP goal if the last available trough SiDBP in the treatment period up to the time point of interest was $<90 \mathrm{~mm} \mathrm{Hg}$ in nondiabetics and $<80 \mathrm{~mm} \mathrm{Hg}$ in diabetics. This study was an estimation study. Therefore, no hypotheses were tested. Assuming that the percentage of patients who reach the BP goal is expected to be within the range of 50-60\%, a study with 400 patients provides estimation for the percentage of patients reaching the BP goal with a precision (that is, half-width of the $95 \%$ confidence interval (CI) for the estimate) of approximately $5.0 \%$; that is, the two-sided $95 \%$ CI for the estimate extends a distance of approximately 5\% from the estimated percentage in both directions. The primary efficacy variable, the percentage of patients who reach the BP goal after 8 weeks of treatment with losartan $50 \mathrm{mg} / \mathrm{HCTZ} 12.5 \mathrm{mg}$ combination therapy, was calculated and a $95 \% \mathrm{CI}$ around the estimated percentage was constructed.

The principal population for analysis of efficacy was the full analysis set cohort, which comprised all patients who took at least one dose of open-label study therapy and had an evaluable measurement for the variable of interest during the treatment period. A patient was also to have a baseline value to be included in the full analysis set population for analysis of change from the baseline. The measurement taken at the end of the screening/baseline period (visit 2) was used as the baseline value. The last available post-baseline measurement obtained during the period of combination treatment up to the time point of interest was used to evaluate efficacy; all such measurements were used, including the data collected at discontinuation and unscheduled visits. Additional inspections of the primary efficacy end point included an 'allcompleters' cohort, comprising only those patients who completed the study.

Secondary end points included mean changes from baseline for SiDBP (key secondary) and sitting SBP (SiSBP), responder rate (percentage of patients who reached the BP goal or at least a 10-mm Hg decrease in SiDBP) after 8 weeks of treatment and the percentage of patients who reached the BP goal after 12 weeks of treatment. Tertiary variables were measured at week 8 and included percentages of patients who reached the $\mathrm{BP}$ goal and responder rates in the subgroups of patients with baseline diabetes, with baseline ECG left ventricular hypertrophy and with baseline obesity (body mass index $>25 \mathrm{~kg} \mathrm{~m}^{-2}$ ); mean 
change in microalbuminuria; and mean change in the Framingham stroke risk score. The key secondary variable, mean change from baseline in SiDBP at week 8 , was estimated and $95 \% \mathrm{CI}$ around the mean change from baseline was calculated. Other secondary and tertiary variables involving change from baseline to end point were analyzed in a manner similar to that of the key secondary variable. Secondary and tertiary variables involving percentages or responder rates were analyzed in a similar way as for the primary efficacy variable.

Compliance was defined as the total number of days the patient took openlabel study therapy divided by the total number of days the patient was supposed to be on therapy during the treatment period (that is, first day to last day of therapy intake).

The assessment of safety and tolerability of the losartan/HCTZ combinations was a specified secondary objective of the study. The safety population comprised all patients enrolled who received at least one dose of open-label study medication. All AEs that started after the first dose of open-label study therapy and up to 14 days after treatment discontinuation were included in the safety analysis.

\section{RESULTS}

\section{Patient characteristics}

The overall disposition of patients enrolled in the study is shown in Figure 1. Of the 512 patients screened for inclusion in the study, 75 were excluded during screening and did not enter the study treatment period. Reasons for exclusion included non-eligibility (for example, non-fulfillment of BP requirements $(n=57)$ ), withdrew consent $(n=13)$, lost to follow-up $(n=4)$, protocol deviation $(n=1)$. The remaining $437(85.4 \%)$ patients met the inclusion criteria and were enrolled at 32 centers within seven countries. The majority of patients were from China and Korea (approximately 60\%): China $24 \%$, Hong Kong 4\%, Korea 35\%, Malaysia 11\%, Philippines $12 \%$, Taiwan $9 \%$ and Thailand $4 \%$. A total of 391 patients $(89.5 \%)$ completed the study.

All patients who were enrolled into the open-label treatment period were included in the baseline characteristics analyses (Table 1). Mean age (s.d.) was 53.0 (10.1) years and mean (s.d.) duration of essential hypertension was 5.2 (7.3) years. Of the 437 enrolled patients, 313 $(71.6 \%)$ had at least one secondary diagnosis. The most common secondary diagnoses included hyperlipidemia (14\%), nonspecific dyslipidemia (6\%), left ventricular hypertrophy (9\%), diabetes mellitus $(11 \%)$, menopause $(10 \%)$, headache $(7 \%)$ and dizziness $(6 \%)$.
Mean baseline BP (s.d.) was 145.3 (13.5) $\mathrm{mm} \mathrm{Hg}$ SiSBP and 95.0 (5.0) $\mathrm{mm}$ Hg SiDBP.

Fifty-five percent of the patients received ARB monotherapy and $48 \%$ received ACEI monotherapy as prior antihypertensive medication. The ARBs (number of patients, mean dose (s.d.)) used prior to losartan/HCTZ combination therapy were candesartan $(n=11$, 8 (0) mg), eprosartan ( $n=11,572$ (90) mg), irbesartan $(n=26,150$ (0) mg), losartan ( $n=125,49$ (9) mg), olmesartan ( $n=3,23$ (15) mg), telmisartan ( $n=23,40(0) \mathrm{mg}$ ) and valsartan ( $n=42,93$ (38) mg). The ACEIs used prior to losartan/HCTZ combination therapy were benazepril ( $n=18,10(0) \mathrm{mg}$ ), captopril ( $n=24,40$ (19) $\mathrm{mg}$ ), cilazapril $(n=8,3$ (1) mg), enalapril $(n=49,9$ (3) mg), fosinopril $(n=7,10(0)$ $\mathrm{mg}$ ), imidapril ( $n=14,9$ (2) $\mathrm{mg})$, lisinopril $(n=10,10$ (5) $\mathrm{mg})$, moexipril $(n=4,7.5(0) \mathrm{mg})$, perindopril $(n=39,4(1) \mathrm{mg})$ and ramipril $(n=23,4(5) \mathrm{mg})$.

Study therapy

After 4 weeks of the study, all 437 patients (100\%) were taking losartan $50 \mathrm{mg} / \mathrm{HCTZ} 12.5 \mathrm{mg}$. After 8 weeks, 250 patients $(57.2 \%)$

Table 1 Baseline characteristics $(n=437)$

\begin{tabular}{|c|c|}
\hline Variable & Value \\
\hline Age, years & 53.0 (10.1); range 22-78 \\
\hline Male gender, $n(\%)$ & $210(48.1)$ \\
\hline Weight, kg & 68.2 (12.1); range $42.6-120.6$ \\
\hline Body mass index, $\mathrm{kg} \mathrm{m}^{-2}$ & 26.0 (3.6); range $0-43$ \\
\hline Sitting systolic BP, mm Hga & 145.3 (13.5); range $109-185$ \\
\hline Sitting diastolic BP, mm Hga & 95.0 (5.0); range $81-110$ \\
\hline Duration of hypertension, years & $5.2(7.3)$; range $0-43$ \\
\hline Prior therapy with ACEIs, $n(\%)$ & $196(44.9)$ \\
\hline Prior therapy with ARBs, $n(\%)$ & $241(55.1)$ \\
\hline History of diabetes, $n(\%)$ & $49(11.2)$ \\
\hline History of left ventricular hypertrophy, $n(\%)$ & $39(8.9)$ \\
\hline Urine albuminuria, $\mathrm{mg} \mathrm{mmol}^{-1}$ creatinine & $4.6(12.2) ;$ range $0-142 ; n=415$ \\
\hline Framingham stroke risk score & 9.1 (3.4); range $2-28$ \\
\hline
\end{tabular}

Abbreviations: ACEls, angiotensin-converting enzyme inhibitors; ARBs, angiotensin receptor blockers; BP, blood pressure.

Data are mean (s.d.) unless otherwise noted.

apatients received ACEI or ARB monotherapy at baseline.

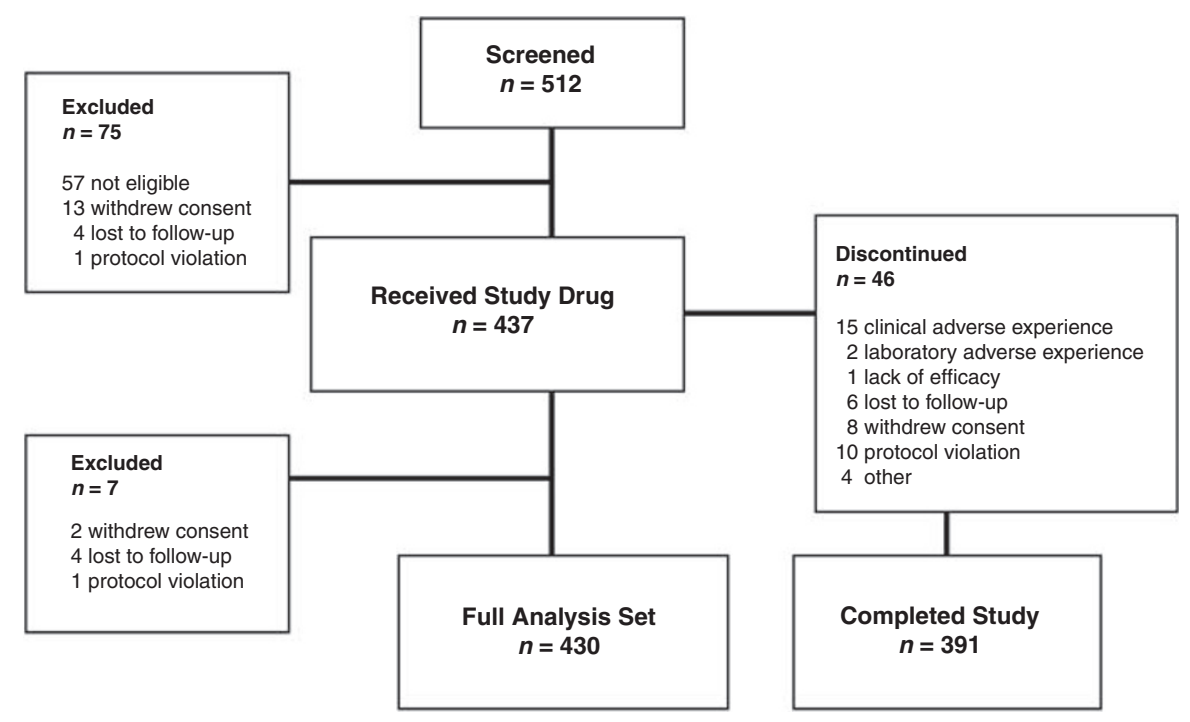

Figure 1 Patient disposition during the trial and reasons for exclusion during baseline periods. 
remained on losartan $50 \mathrm{mg} / \mathrm{HCTZ} 12.5 \mathrm{mg}, 163$ (37.3\%) were taking losartan $100 \mathrm{mg} / \mathrm{HCTZ} 12.5 \mathrm{mg}$, and $1(0.2 \%)$ patient was taking losartan $100 \mathrm{mg} / \mathrm{HCTZ} 25 \mathrm{mg}$. At study end (12 weeks), 232 patients (53.1\%) remained on losartan $50 \mathrm{mg} / \mathrm{HCTZ} 12.5 \mathrm{mg}, 96$ (22.0\%) were taking losartan $100 \mathrm{mg} / \mathrm{HCTZ} 12.5 \mathrm{mg}$, and 65 (14.9\%) patients were taking losartan $100 \mathrm{mg} / \mathrm{HCTZ} 25 \mathrm{mg}$. Patient compliance with the study therapy was good (data not shown).

\section{BP goal attainment and responder rates}

The percentage of patients who reached the BP goal (trough SiDBP $<90 \mathrm{~mm} \mathrm{Hg}$ in non-diabetics; $<80 \mathrm{~mm} \mathrm{Hg}$ in diabetics) after 8 weeks of treatment with losartan/HCTZ combination therapy (up to losar$\tan 100 \mathrm{mg} / \mathrm{HCTZ} 12.5 \mathrm{mg}$ ), the primary variable, was $73.5 \%$ (95\% CI: 69.0-77.6) (Figure 2). Results of secondary analysis based on the cohort of patients who completed the study corroborated those obtained with the full analysis set approach. After 4 weeks and 12 weeks, the BP goal was attained by 63.4 and $78.1 \%$ of patients, respectively (Figure 2). Similar results were found in every subgroup analysis, including gender, age category, country, baseline SiDBP, baseline SiSBP and earlier use of antihypertensive drugs (data not shown).

The responder rate (percentage of patients who reached the BP goal or had at least a $10-\mathrm{mm} \mathrm{Hg}$ decrease in SiDBP) after 8 weeks of treatment was $78.1 \%$ (95\% CI: 73.9-82.0). After 4 and 12 weeks, the responder rates were 67.8 and $83.3 \%$, respectively (Figure 2).

Similar results with respect to the BP goal and responder rates were found after 8 weeks of treatment in the sub-populations of patients with baseline left ventricular hypertrophy and with baseline obesity. In the subgroup of diabetic patients, the BP goal was attained by $47.9 \%$, whereas the responder rate was $64.6 \%$. At the end of the study (week 12), $94 / 430$ patients $(22 \%)$ were non-responders (that is, not at BP goal). Of those 94 non-responders, 21 were diabetics (at week 12, 27 of the 48 diabetics reached the BP goal).

\section{Changes in BP at weeks 4,8 and 12 and other parameters}

Sitting SBP/DBP were significantly reduced (mean change from baseline, $P<0.001)$ at week $4(-14.5 /-10.2 \mathrm{~mm} \mathrm{Hg}$, titrated up to

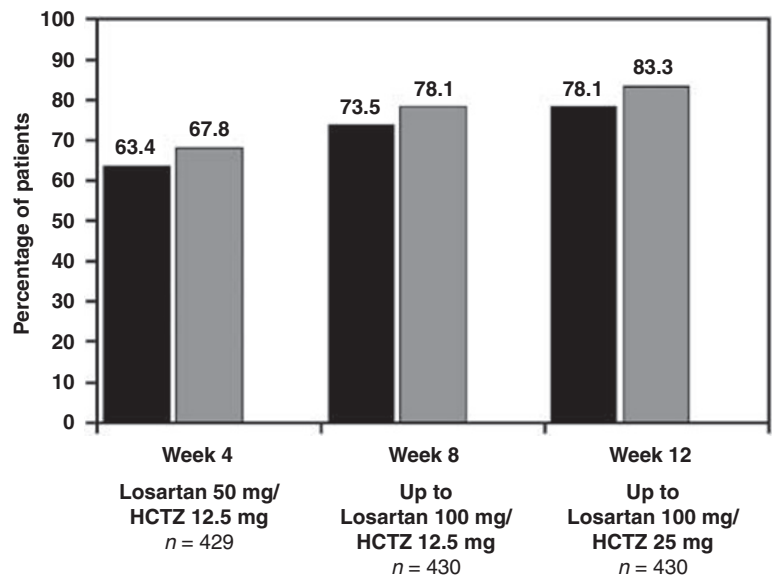

Figure 2 Asian patients with blood pressure uncontrolled with usual doses of monotherapy with an angiotensin-converting enzyme inhibitor or angiotensin receptor blocker who achieved blood pressure goal (black bars; trough sitting diastolic blood pressure $<90 \mathrm{~mm} \mathrm{Hg}$ in non-diabetics and $<80 \mathrm{~mm} \mathrm{Hg}$ in diabetics) or response (gray bars; trough sitting diastolic blood pressure $<90 \mathrm{~mm} \mathrm{Hg}$ in non-diabetics and $<80 \mathrm{~mm} \mathrm{Hg}$ in diabetics or reduction of sitting diastolic blood pressure $\geqslant 10 \mathrm{mmHg}$ ) after monotherapy was switched to losartan/hydrochlorothiazide combination therapy. losartan $50 \mathrm{mg} / \mathrm{HCTZ} \quad 12.5 \mathrm{mg})$, week $8 \quad(-16.7 /-12.1 \mathrm{~mm} \mathrm{Hg}$, titrated up to losartan $100 \mathrm{mg} / \mathrm{HCTZ} 12.5 \mathrm{mg})$ and week $12(-17.7 /$ $-12.6 \mathrm{~mm} \mathrm{Hg}$, titrated up to losartan $100 \mathrm{mg} / \mathrm{HCTZ} 25 \mathrm{mg}$ ) (Table 2, Figure 3). Reductions from baseline in StSBP and StDBP were seen after 8 weeks of treatment with the losartan/HCTZ combination; mean change from baseline in StSBP and StDBP was -15.8 and $-10.8 \mathrm{~mm} \mathrm{Hg}$, respectively.

Reduction from baseline in microalbuminuria was seen after 8 weeks of treatment with losartan/HCTZ; mean change from baseline was $-1.43 \mathrm{mg} \mathrm{mmol}^{-1}$ creatinine ( $95 \% \mathrm{CI}:-2.82$ to -0.05 ). The Framingham stroke risk score was also reduced after 8 weeks of treatment; the mean change from baseline was -2.28 (95\% CI: -2.46 to -2.11$)$. After 4 and 12 weeks, the mean changes from baseline were -1.98 and -2.44 , respectively. At the end of 12 weeks, the Framingham stroke risk score changes from baseline were -2.22 in men and -2.65 in women.

\section{Safety}

All 437 patients were available for the safety analysis. The mean number of days on treatment was approximately 81 . During the entire treatment period, $120(27.5 \%)$ and $88(21.0 \%)$ patients experienced one or more clinical and laboratory $\mathrm{AE}$, respectively. Upper respiratory tract infection $(n=15,3.4 \%)$, dizziness $(n=15,3.4 \%)$ and headache $(n=12,2.7 \%)$ were the most frequently recorded clinical AEs. Thirty-seven patients $(8.5 \%)$ experienced at least one clinical AE that was considered possibly, probably or definitely drug related. Eleven (2.5\%) serious AEs were recorded. One patient had two serious events (dizziness and nephropathy) that were considered definitely drug related; the patient made a full recovery but discontinued the study. Another patient experienced a serious AE of severe cellulitis leading to discontinuation. No death occurred during the study.

During the entire treatment period, laboratory AEs were identified in 88 patients $(21.0 \%)$. None of these events was classified as serious and only two patients discontinued therapy (one patient experienced increased alanine aminotransferase and increased aspartate aminotransferase, and one patient experienced increased alanine aminotransferase). Increase in blood alanine aminotransferase $(n=18,4.3 \%)$, uric acid $(n=21,5.0 \%)$, glycosylated $\mathrm{Hb}$ (HbAlc) ( $n=21,5.0 \%)$, glucose $(n=14,3.3 \%)$ and urine albumin $(n=9,2.9 \%)$ were the most frequently reported laboratory AEs. Laboratory AEs that were considered to be possibly related to study medication were recorded in 30 patients $(7.1 \%)$ (Table 3$)$. These were mainly increased blood uric acid $(n=18)$ and blood urea nitrogen $(n=7)$. No clinically meaningful changes in hematological variables were observed.

\section{DISCUSSION}

The present results show that the majority (73.5\%) of Asian patients who were previously not at goal DBP on usual doses of ACE inhibitor or ARB monotherapy reached the primary end point of goal BP of DBP $<90 \mathrm{~mm} \mathrm{Hg}$ for non-diabetics and $<80 \mathrm{~mm} \mathrm{Hg}$ for diabetics when switched to losartan $50-100 \mathrm{mg} / \mathrm{HCTZ} 12.5 \mathrm{mg}$ combination therapy for 8 weeks. In addition, $78.1 \%$ of patients responded to combination therapy at week 8 , which was defined as DBP $<90 \mathrm{~mm} \mathrm{Hg}$ for non-diabetics and $<80 \mathrm{~mm} \mathrm{Hg}$ for diabetics or $\geqslant 10-\mathrm{mm} \mathrm{Hg}$ reduction in DBP. The majority of clinical experience with the losartan/HCTZ combination is with losartan $50 \mathrm{mg} / \mathrm{HCTZ}$ $12.5 \mathrm{mg}$ in non-Asian patients. The only previously published study with the losartan $100 \mathrm{mg} / \mathrm{HCTZ} 12.5 \mathrm{mg}$ combination is in non-Asian patients. ${ }^{17}$ Patients whose BP was inadequately controlled (DBP 95$120 \mathrm{~mm} \mathrm{Hg}$ ) with losartan $100 \mathrm{mg}$ monotherapy were randomized to continuation of losartan $100 \mathrm{mg}$ monotherapy vs. losartan $100 \mathrm{mg} /$ 
Table 2 Summary of changes from baseline in blood pressure, mean (s.d.)

\begin{tabular}{lclll}
\hline Treatment & Study week & Screening/baseline SiSBP/SiDBP & Baseline/treatment SiSBP/SiDBP & Change SiSBP/SiDBP \\
\hline ACEI or ARB monotherapy & -1 to 0 & $146.5(13.1) / 95.6(5.2)$ & $145.4(13.4) / 95.0(5.0)$ & $-1.1 /-0.6$ \\
Losartan 50 mg/HCTZ 12.5 mg & $0-4$ & $145.4(13.4) / 95.0(5.0)$ & $130.9(14.5) / 84.8(8.8)$ & $-14.5(0.6) /-10.2(0.4)$ \\
Up to losartan $100 \mathrm{mg} / \mathrm{HCTZ} 12.5 \mathrm{mg}$ & $4-8$ & $145.4(13.4) / 95.0(5.0)$ & $128.7(16.7) / 82.9(8.9)$ & $-16.7(0.7) /-12.1(0.4)$ \\
Up to losartan $100 \mathrm{mg} / \mathrm{HCTZ} 25 \mathrm{mg}$ & $8-12$ & $145.4(13.4) / 95.0(5.0)$ & $127.7(13.5) / 82.4(8.3)$ & $-17.7(0.7) /-12.6(0.4)$ \\
\hline
\end{tabular}

Abbreviations: ACEI, angiotensin-converting enzyme inhibitor; ARB, angiotensin receptor blocker; HCTZ, hydrochlorothiazide; SiDBP, sitting diastolic blood pressure; SiSBP, sitting systolic blood pressure.

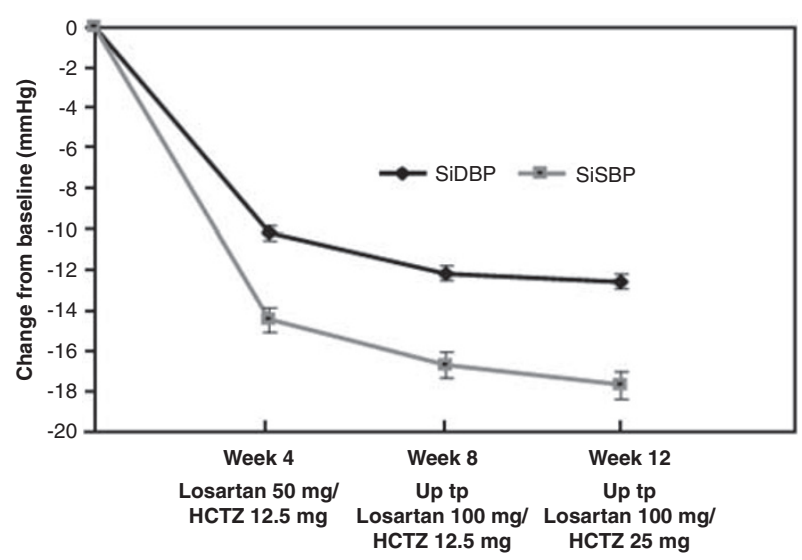

Figure 3 Mean change from baseline (mean \pm s.e.) in sitting diastolic blood pressure (SiDBP) and sitting systolic blood pressure (SiSBP) after 4, 8 and 12 weeks of losartan/HCTZ combination therapy.

Table 3 Laboratory adverse effects: possibly, probably or definitely drug related

\begin{tabular}{lcc}
\hline & 8-week period (\%) & 12-week period (\%) \\
\hline Patients with one or more AEs & $18 / 420(4.3)$ & $30 / 420(7.1)$ \\
& & \\
Hematological test & $1 / 417(0.2)$ & $1 / 417(0.2)$ \\
Hematocrit decreased & $2 / 418(0.5)$ & $3 / 420(0.7)$ \\
Hemoglobin decreased & & \\
& & \\
Blood chemistry test & $2 / 420(0.5)$ & $2 / 420(0.5)$ \\
Alanine aminotransferase increased & $2 / 420(0.5)$ & $2 / 420(0.5)$ \\
Aspartate aminotransferase increased & - & $1 / 420(0.2)$ \\
Blood creatinine increased & $2 / 418(0.5)$ & $3 / 418(0.7)$ \\
Blood glucose increased & $2 / 420(0.5)$ & $3 / 420(0.7)$ \\
Blood potassium decreased & $4 / 292(1.4)$ & $7 / 292(2.4)$ \\
Blood urea nitrogen increased & $11 / 416(2.6)$ & $18 / 416(4.3)$ \\
Blood uric acid increased & - & $1 / 420(0.2)$ \\
Creatine phosphokinase increased & - & $1 / 417(0.2)$ \\
Hemoglobin A1C increased & & \\
Urinalysis test & $1 / 310(0.3)$ & $1 / 310(0.3)$ \\
Albumin urine present &
\end{tabular}

All values were determined by the investigator to be possibly, probably or definitely drug related.

HCTZ $12.5 \mathrm{mg}$. After 6 weeks, 55.5\% of the combination therapy group and $42.4 \%$ of the monotherapy group achieved goal BP (SiDBP $<90 \mathrm{~mm} \mathrm{Hg}$ ), whereas $63 \%$ responded (mean trough DBP $<90$ or $\geqslant 10$ - $\mathrm{mm} \mathrm{Hg}$ decrease in mean trough DBP) in the combination therapy group and $44.4 \%$ responded in the monotherapy group.
In this study, $63.4 \%$ of Asian patients reached the BP goal with losartan $50 \mathrm{mg} / \mathrm{HCTZ} 12.5 \mathrm{mg}$ after 4 weeks, whereas $67.8 \%$ responded. These results are consistent with two earlier studies in non-Asian patients who were treated for 6 weeks with losartan $50 \mathrm{mg}$ and with therapy titrated if DBP $>90 \mathrm{~mm} \mathrm{Hg}$ to either losartan $100 \mathrm{mg}$ or losartan $50 \mathrm{mg} / \mathrm{HCTZ} 12.5 \mathrm{mg}$ for an additional 6 weeks. $^{18,19}$ In the first study, 70\% responded (DBP $<90 \mathrm{~mm} \mathrm{Hg}$ or $\geqslant 90 \mathrm{~mm} \mathrm{Hg}$ and reduction DBP $>10 \mathrm{~mm} \mathrm{Hg}$ ) with losartan $50 \mathrm{mg} / \mathrm{HCTZ} 12.5 \mathrm{mg}$ combination therapy and $60 \%$ responded with losartan $50-100 \mathrm{mg}$ monotherapy. ${ }^{18}$ In the second study, $76.8 \%$ responded with combination therapy and $73.1 \%$ with monotherapy. ${ }^{19}$ In a study of patients of Asian descent with baseline DBP 95-115 $\mathrm{mm} \mathrm{Hg}$ and SBP $<190 \mathrm{~mm} \mathrm{Hg}, 26.8 \%$ reached the BP goal of DBP $<90 \mathrm{~mm} \mathrm{Hg}$ after 4 weeks of valsartan $80 \mathrm{mg}$ monotherapy. Patients not at goal were switched to losartan $50 \mathrm{mg} / \mathrm{HCTZ} 12.5 \mathrm{mg}$ for 4 weeks after which $72 \%$ reached the goal. ${ }^{20}$ In a recent report, treatment for Japanese patients whose BP was uncontrolled ( $24 \mathrm{~h}$ ambulatory $\mathrm{BP} \geqslant 135 / 80 \mathrm{~mm} \mathrm{Hg}$ ) after $\geqslant 2$ months of treatment with either candesartan $8 \mathrm{mg}$ or amlodipine $5 \mathrm{mg}$ was switched to losartan $50 \mathrm{mg} / \mathrm{HCTZ} 12.5 \mathrm{mg}$. Twenty-four hours BP decreased significantly in both groups after 3 and 12 months of losartan/ HCTZ treatment. There were significant decreases in SBP in both groups during the daytime (0600-2130 hours), night time (2200-0530 hours) and early morning (0600-0800 hours) after 12 months of losartan/HCTZ treatment. ${ }^{21}$

Losartan $100 \mathrm{mg} / \mathrm{HCTZ} 25 \mathrm{mg}$ was the highest dose combination in this study and its optional use increased the percentage of patients who reached the goal to $78.1 \%$ and increased the response rate to 83.3\%. Experience with this dose combination in non-Asians includes a study in which patients whose BP was uncontrolled (DBP $>90 \mathrm{~mm} \mathrm{Hg}$ ) with simultaneous treatment with at least two singleagent drugs were switched to losartan $100 \mathrm{mg} / \mathrm{HCTZ} 25 \mathrm{mg}$. Control (DBP $\leqslant 90 \mathrm{~mm} \mathrm{Hg}$ ) and responder (DBP $<90 \mathrm{~mm} \mathrm{Hg}$ or reduction of DBP $\geqslant 10 \mathrm{~mm} \mathrm{Hg}$ ) rates were 63.0 and $82.1 \%$, respectively, at 12 weeks. ${ }^{22}$ In a study of untreated patients with moderate-to-severe essential hypertension or patients with uncontrolled hypertension despite treatment with monotherapy or low-dose combination, the response rate to losartan $100 \mathrm{mg} / \mathrm{HCTZ} 25 \mathrm{mg}$ therapy was $87.8 \%$ (BP lowering $>5 \mathrm{~mm} \mathrm{Hg}$ of either $24 \mathrm{~h} \mathrm{SBP}$ or $24 \mathrm{~h} \mathrm{DBP}$ average values) after 8 weeks. $^{23}$

Current and prior clinical experience have shown that treatment with the losartan/HCTZ combination treatment can achieve clinically significant reductions of $\mathrm{BP}$ in Asian patients and that the magnitude of the reductions are consistent with those in non-Asian patients. Lower BPs are associated with reduced risk of cardiovascular events; ${ }^{24}$ however, there are no end point studies carried out with losartan exclusively in Asian patients.

Urinary protein measurements may be important to assess patient risk and to determine the need to change therapy. ${ }^{25}$ The spot method of urine collection and use of urinary albumin-creatinine ratio used in this study provided a convenient way to assess the effectiveness of 
treatment. ${ }^{26}$ Baseline urinary protein excretion was low (4.65 $\mathrm{mg} \mathrm{mmol}^{-1}$ creatinine) in this study, likely reflecting the limited number of diabetics (11\%) and the younger age group (mean age 53 years). Urinary protein excretion was reduced by $1.43 \mathrm{mg} \mathrm{mmol}^{-1}$ creatinine at 8 weeks (titration up to losartan $100 \mathrm{mg} / \mathrm{HCTZ}$ $12.5 \mathrm{mg}$ ). In a recent study in Asian patients with nephropathy, there were different dose-response relationships for BP vs. reduction in proteinuria. ${ }^{15}$ In that study, losartan 50 and $100 \mathrm{mg}$ were comparable in lowering BP but losartan $100 \mathrm{mg}$ showed a greater reduction in proteinuria in patients with all ACE polymorphs.

There are limitations of this trial. This was an open-label trial with no comparator group. It is possible that some of the reductions in BP observed were because of a placebo effect. To minimize this possibility, patients were required to be on prior monotherapy for at least 4 weeks prior to screening and were instructed to stay on prior monotherapy for 1 week prior to initiation of study treatment. Patients were not enrolled if DBP varied more than $5 \mathrm{~mm} \mathrm{Hg}$ at the two screening/ baseline visits. The mean difference (s.d.) between the two visits of enrolled patients was $<1 \mathrm{~mm} \mathrm{Hg}$ (DBP 95.6 (5.2) $\mathrm{mm} \mathrm{Hg}$ at visit 1 and 95.0 (5.0) $\mathrm{mm} \mathrm{Hg}$ at visit 2), indicative of BP stability during the screening period. Patient compliance was very good in this study as evaluated by investigator pill count at each visit. This may have contributed to the BP reductions observed. It should also be noted that BP was measured at trough (for example, 22-26h after the last dose). Investigators agreed to call patients before each visit reminding them not to take the treatment on the morning of the visit and to schedule the visit in the morning. This procedure may have increased the compliance and therefore the treatment response.

\section{Conclusions}

Switching Asian patients who were currently not at BP goal on their previous treatment with ARB or ACEI monotherapy to losartan/ HCTZ combinations significantly reduced BP, achieving the BP goal in the majority of patients. These findings are consistent with earlier findings in non-Asian populations. The losartan/HCTZ combination was generally well tolerated in Asian patients, consistent with earlier findings in non-Asian populations.

\section{CONFLICT OF INTEREST}

This study was sponsored and fully funded by Merck and Co. Inc., Whitehouse Station, NJ, USA, as Losartan Protocol 950. The sponsor was involved in the design and conduct of the study and the collection of the data. The analyses were carried out by Rachid Massaad, who is an employee of Merck. All authors had full access to the data and were involved in the analyses and interpretation of the data and preparation and final approval of the paper. Drs Kee-Sik Kim, Wei Hu Fan, YoungDae Kim, Wenling Zhu, Yen Yew Ngau, Peter Tong, Byung-Soo Kim, Maureen Santos, Wei-Hsiang Lin and Peera Buranakitjaroen received grants from Merck as investigators for the study. Dr Ronald D Smith and Rashid Massaad are or were employees of Merck and may own stock or have stock options with the company.

\section{ACKNOWLEDGEMENTS}

We thank Maria Vala and Verle Coenen for critical involvement in the clinical site coordination and data management of the trial, and Paulette A Lyle for assistance with the preparation of the paper. Author's contributions: Kee-Sik Kim, Wei Hu Fan, Young-Dae Kim, Wenling Zhu, Yen Yew Ngau, Peter Tong, Byung-Soo Kim, Maureen Santos, Wei-Hsiang Lin and Peera Buranakitjaroen (study investigator, interpretation of data, revision and approval of paper); Rachid Massaad (protocol design, statistical data analysis, interpretation of data, drafting and approval of paper); and Ronald D Smith (protocol design, interpretation of data, drafting and approval of paper).

1 Martiniuk AL, Lee CM, Lawes CM, Ueshima H, Suh I, Lam TH, Gu D, Feigin V, Jamrozik $\mathrm{K}$, Ohkubo T, Woodward M. Hypertension: its prevalence population-attributable fraction for mortality from cardiovascular disease in the Asia-Pacific region. $J$ Hypertens 2007; 25: 73-79.

2 Whitworth JA, World Health Organization, International Society of Hypertension Writing Group. 2003 World Health Organization (WHO)/International Society of Hypertension (ISH) statement on management of hypertension. J Hypertens 2003; 21: 1983-1992.

3 Chobanian AV, Bakris GL, Black HR, Cushman WC, Green LA, Izzo Jr JL, Jones DW, Materson BJ, Oparil S, Wright Jr JT, Roccella EJ. The Seventh Report of the Joint National Committee on Prevention, Detection, Evaluation, and Treatment of High Blood Pressure: the JNC 7 report. JAMA 2003; 289: 2560-2572.

4 Mancia G, De Backer G, Dominiczak A, Cifkova R, Fagard R, Germano G, Grassi G, Heagerty AM, Kjeldsen SE, Laurent S, Narkiewicz K, Ruilope L, Rynkiewicz A, Schmieder RE, Boudier HA, Zanchetti A, Vahanian A, Camm J, De Caterina R, Dean V, Dickstein K, Filippatos G, Funck-Brentano C, Hellemans I, Kristensen SD, McGregor K, Sechtem U, Silber S, Tendera M, Widimsky P, Zamorano JL, Erdine S, Kiowski W, Agabiti-Rosei E, Ambrosioni E, Lindholm LH, Viigimaa M, Adamopoulos S, Agabiti-Rosei E, Ambrosioni E, Bertomeu V, Clement D, Erdine S, Farsang C, Gaita D, Lip G, Mallion JM, Manolis AJ, Nilsson PM, O'Brien E, Ponikowski P, Redon J, Ruschitzka F, Tamargo J, van Zwieten P, Waeber B, Williams B. 2007 Guidelines for the Management of Arterial Hypertension. The Task Force for the Management of Arterial Hypertension of the European Society of Hypertension (ESH) and of the European Society of Cardiology (ESC). J Hypertens 2007; 25: 1105-1187.

5 Waeber B. Position of fixed-dose combinations containing an AT(1)-receptor blocker and a thiazide diuretic. Blood Press 2005; 14: 324-336.

6 Ram CV. Antihypertensive efficacy of angiotensin receptor blockers in combination with hydrochlorothiazide: a review of the factorial-design studies. J Clin Hypertens (Greenwich) 2004; 6: 569-577

7 Goa KL, Wagstaff AJ. Losartan potassium: a review of its pharmacology, clinical efficacy and tolerability in the management of hypertension. Drugs 1996; 51: 820-845.

8 Benedict CR. Safe and effective management of hypertension with fixed-dose combination therapy: focus on losartan plus hydrochlorothiazide. Int J Clin Pract 2000; 54: 48-54.

9 Dahlof B, Zanchetti A, Diez J, Nicholls MG, Yu CM, Barrios V, Aurup P, Smith RD, Johansson M. Effects of losartan and atenolol on left ventricular mass and neurohormonal profile in patients with essential hypertension and left ventricular hypertrophy. J Hypertens 2002; 20: 1855-1864, J Hypertens 2002; 20: 2315.

10 Hou FF, Xie D, Zhang X, Chen PY, Zhang WR, Liang M, Guo ZJ, Jiang JP. Renoprotection of Optimal Antiproteinuric Doses (ROAD) study: a randomized controlled study of benazepril and losartan in chronic renal insufficiency. J Am Soc Nephrol 2007; 18 : 1889-1898

11 Brenner BM, Cooper ME, de Zeeuw D, Keane WF, Mitch WE, Parving HH, Remuzzi G, Snapinn SM, Zhang Z, Shahinfar S. Effects of losartan on renal and cardiovascular outcomes in patients with type 2 diabetes and nephropathy. N Engl J Med 2001; 345 : 861-869.

12 Dahlöf B, Devereux RB, Kjeldsen SE, Julius S, Beevers G, de Faire U, Fyhrquist F, Ibsen $\mathrm{H}$, Kristiansson K, Lederballe-Pedersen O, Lindholm LH, Nieminen MS, Omvik P, Oparil S, Wedel H. Cardiovascular morbidity and mortality in the Losartan Intervention For Endpoint reduction in hypertension study (LIFE): a randomised trial against atenolol. Lancet 2002; 359: 995-1003.

13 Andersen S, Rossing P, Juhl TR, Deinum J, Parving HH. Optimal dose of losartan for renoprotection in diabetic nephropathy. Nephrol Dial Transplant 2002; 17: 1413-1418.

14 Laverman GD, Henning RH, de Jong PE, Navis G, de Zeeuw D. Optimal antiproteinuric dose of losartan in nondiabetic patients with nephrotic range proteinuria. Am J Kidney Dis 2001; 38: 1381-1384.

15 Park HC, Choi HY, Kim BS, Kang SW, Choi KH, Ha SK, Lee HY, Han DS, effect of losartan in non-diabetic renal disease is not dependent on ACE insertion/deletion polymorphism. Kidney Blood Press Res 2006; 29: 216-224.

16 Fukuda M, Kimura G. Pathophysiology of antihypertensive therapy with diuretics. Hypertens Res 2006; 29: 645-653.

17 Gleim GW, Rubino J, Zhang H, Shahinfar S, Soffer BA, Lyle PA, Littlejohn III TW, Feig PU. A multicenter, randomized, double-blind, parallel-group trial of the antihypertensive efficacy and tolerability of a combination of once-daily losartan $100 \mathrm{mg} /$ hydrochlorothiazide $12.5 \mathrm{mg}$ compared with losartan $100 \mathrm{mg}$ monotherapy in the treatment of mild to severe essential hypertension. Clin Ther 2006; 28: $1639-1648$.

18 Dahlöf B, Lindholm LH, Carney S, Pentikäinen PJ, Ostergren J. Main results of the losartan versus amlodipine (LOA) study on drug tolerability and psychological general well-being. LOA Study Group. J Hypertens 1997; 15: 1327-1335.

19 Manolis AJ, Grossman E, Jelakovic B, Jacovides A, Bernhardi DC, Cabrera WJ, Watanabe LA, Barragan J, Matadamas N, Mendiola A, Woo KS, Zhu JR, Mejia AD, Bunt T, Dumortier T, Smith RD. Effects of losartan and candesartan monotherapy and losartan/hydrochlorothiazide combination therapy in patients with mild to moderate hypertension. Losartan Trial Investigators. Clin Ther 2000; 22: 1186-1203. 
20 Watanabe LA, Wei M, Sun N, Kim D, Chiang CE, Ke Y, Tseng CD, Coloma R, Vala M, Massaad R, Feig P, Guptha S. Effect on blood pressure control of switching from valsartan monotherapy to losartan/hydrochlorothiazide in Asian patients with hypertension: results of a multicentre open-label trial. Curr Med Res Opin 2006; 22 : 1955-1964.

21 Minami J, Abe C, Akashiba A, Takahashi T, Kameda T, Ishimitsu T, Matsuoka H. Longterm efficacy of combination therapy with losartan and low-dose hydrochlorothiazide in patients with uncontrolled hypertension. Int Heart J 2007; 48: 177-186.

22 Naidoo DP, Sareli P, Marin F, Aroca-Martinez G, Maritz FJ, Jardim PC, Guerrero AA, Thompson CA, Bero T, Drazka J, Kosmalova V, Dumortier T, Smith RD. Increased efficacy and tolerability with losartan plus hydrochlorothiazide in patients with uncontrolled hypertension and therapy-related symptoms receiving two monotherapies. Adv Ther 1999; 16: 187-199.

23 Coca A, Sobrino J, Soler J, Felip A, Pelegri A, Mínguez A, Vila J, de la Sierra A, Plana J. Trough-to-peak ratio, smoothness index, and circadian blood pressure profile after treatment with once-daily fixed combination of losartan 100 and hydrochlorothiazide 25 in essential hypertension. J Cardiovasc Pharmacol 2002; 39: 824-833.

24 Lawes CM, Rodgers A, Bennett DA, Parag V, Suh I, Ueshima H, MacMahon S. Blood pressure and cardiovascular disease in the Asia Pacific region. J Hypertens 2003; 21 : 707-716.

25 Bramlage P, Thoenes M, Paar WD, Bramlage CP, Schmieder RE. Albuminuria: an indicator of cardiovascular risk. Med Klin (Munich) 2007; 102: 833-843.

26 Jafar TH, Chaturvedi N, Hatcher J, Levey AS. Use of albumin creatinine ratio and urine albumin concentration as a screening test for albuminuria in an Indo-Asian population. Nephrol Dial Transplant 2007; 22: 2194-2200.

\section{APPENDIX}

Asia HEAALTH Study Investigators and Institutions (by country)

China: Fan, Wei Hu, Huashan Hospital, Shanghai, China; Zhu, Wenling, Peking Union Medical College Hospital, Beijing, China; Zhao, Yusheng, General Hospital of PLA, Beijing; Cai, Naisheng, Zhong Shan Hospital, Shanghai; Zheng, Xing, Shanghai Second Medical University, Shanghai.

Hong Kong: Tong, Peter Prince of Wales Hospital, The Chinese University of Hong Kong.
Republic of Korea: Kim, Kee-Sik, Daegu Catholic University Medical Center, Daegu; Kim, Byung-Soo, Dae-Dong Hospital, Busan; Kim, Young-Dae, Dong-A University Hospital, Busan; Hwang, Jin-Yong, Gyeongsang National University, JinJu; Jung, Byung Chun, Daegu Fatima Hospital, Daegu; Kim, Byung Soo, Daedong Hospital, Busan; Oh, Ju Hyeon, Samsung Medical Center, Masan; Lee, Su-Hun, Ulsan Dong Kang General Hospital, Ulsan; Han, Seong-Wook, Dongsan Medical Center, Daegu; Kim, Tae Ik, Maryknoll General Hospital, Busan; Kim, Dongsoo, Inje University Busan-Paik Hospital, Busan; Shin, Eun-Seok, Ulsan University Hospital, Ulsan; Shin, Dong-Gu, Yeungnam University Medical Center, Daegu; Park, Joong Il, II, Seoul Veterans Hospital, Seoul.

Malaysia: Ngau, Yen Yew, Hospital Kuala Lumpur; Rosman, Azmillah, Hospital Selayang, Batu Caves; Mahadasa, Phanindranath, Hospital Queen Elizabeth, Kota Kinabalu; Lee, Chuey Yan, Hospital Sultanah Aminah, Johor Bahru.

Philippines: Santos, Maureen, Cebu Doctors' University Hospital; Habaluyas, Ramoncito, Amang Rodriguez Medical Center, Marikina City.

Taiwan: Lin, Wei-Hsiang, Tri-Service General Hospital, Taipei City; Kelvin Hsieh, Chang-Gung Memorial Hospital, Kaohsiung; Wu, Chau-Chung, E-DA Hospital, Kaohsiung; Chou, Hsiang-Tai, China Medical University Hospital, Taichung; Yin, Wei-Hsian, Cheng Hsin Rehabilitation Medical Center, Taipei.

Thailand: Buranakitjaroen, Peera, Siriraj Hospital, Mahidol University, Bangkok, Thailand; Pienvichit, Pavit, Ramathibodi Hospital, Bangkok. 